Review

\title{
Anti-CD 20 monoclonal antibody (rituximab) treatment for inflammatory ocular diseases
}

\author{
E. Miserocchi ${ }^{\text {a,* }}$, I. Pontikaki ${ }^{\text {b,c }}$, G. Modorati a ${ }^{\text {, M. Gattinara }}{ }^{\text {b,c }}$, P.L. Meroni ${ }^{\text {b }}$, V. Gerloni ${ }^{\text {b,c }}$ \\ a Department of Ophthalmology, University Vita-Salute, Scientific Institute San Raffaele, Milan, Italy \\ ${ }^{\mathrm{b}}$ Department of Rheumatology, Istituto Ortopedico G. Pini University of Milan, Italy \\ c Pediatric Rheumatology Unit, Istituto Ortopedico G. Pini University of Milan, Italy
}

\section{A R T I C L E I N F O}

\section{Article history:}

Received 28 June 2011

Accepted 5 July 2011

Available online 13 July 2011

\section{Keywords:}

Rituximab

Ocular inflammatory diseases

Juvenile idiopathic arthritis

\begin{abstract}
A B S T R A C T
Rituximab is a monoclonal antibody directed against the CD20 antigen expressed on B cells and widely used in the treatment of non-Hodgkin's lymphoma and rheumatoid arthritis.

There is a growing amount of literature which suggests that rituximab may be useful for inflammatory ocular diseases and intraocular lymphoma. Few cases have been reported on treatment of refractory scleritis, peripherative ulcerative keratitis, uveitis and ocular surface inflammatory disorders. Rituximab may be effective in the treatment of ocular inflammatory diseases in particular the most aggressive, recalcitrant and sight-threatening forms of inflammation such as uveitis associated to juvenile idiopathic arthritis.

We review the literature covering the use of Rituximab in these conditions and report our results on the efficacy of Rituximab in the treatment of 8 children with very severe and long-standing uveitis who failed to respond to one or more TNF blockers. Our patients showed improvement in activity of uveitis, reduction of concomitant corticosteroids and immunosuppressants after a mean follow-up time of 14.87 months on rituximab. No serious adverse events were encountered in our treated patients.

Although further studies are needed for assessing the efficacy of rituximab and the exact dosing regimen, rituximab may be considered as a treatment alternative in patients with the most aggressive forms of inflammatory ocular diseases who fail to respond to conventional and anti-TNF immunosuppressive agents. (c) 2011 Elsevier B.V. All rights reserved.
\end{abstract}

\section{Contents}

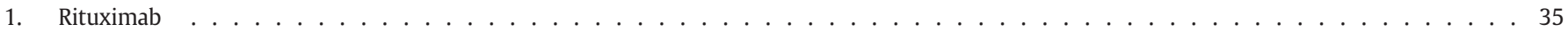

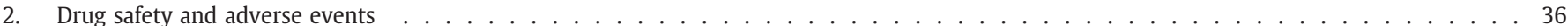

3. Rituximab in systemic autoimmune diseases $\ldots \ldots \ldots \ldots$

4. Rituximab in inflammatory eye diseases . . . . . . . . . . . . . . . . . . . . . . . . . . . . . . . 36

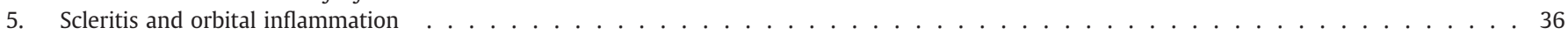

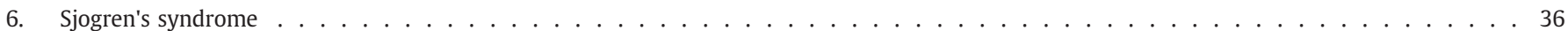

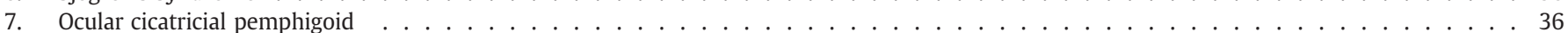

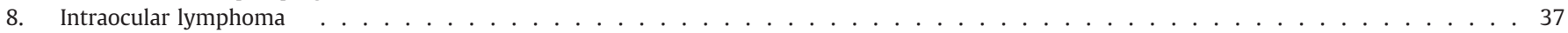

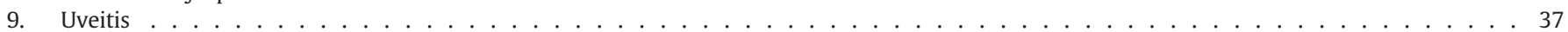

10. Children with juvenile idiopathic arthritis associated uveitis: personal experience . . . . . . . . . . . . . . . . . . . . . . . . . 37

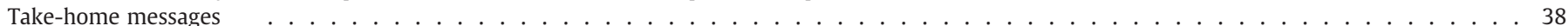

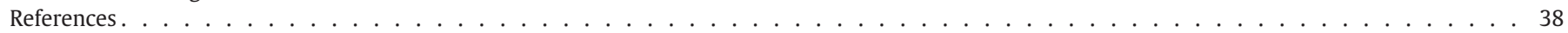

* Corresponding author at: Department of Ophthalmology, Scientific Institute San Raffaele, University Vita-Salute, Via Olgettina 60, 20132 Milan, Italy. Tel.: + 3902 26433512; fax: + 390226433643

E-mail address: miserocchi.elisabetta@hsr.it (E. Miserocchi).

\section{Rituximab}

Anti CD20 Rituximab is a chimeric (murine and human) monoclonal antibody directed against the CD20 molecule, a tetraspan membrane protein found only on the surface of mature B cells [1-6]. The CD20 molecule displays a dynamic appearance first evolving in the immature 
B cell stage and later disappearing when B cells differentiate into plasma cells. By targeting CD20 the killing of B-cell precursor stem cells is avoided. Long-lived plasma cells residing in the bone marrow are also spared as most of them do not any longer carry the CD20 antigen. This means that immunoglobulin formation against isoantigens and antibodies against previously fought infectious agents are continuously formed. The mechanism at which Rituximab causes B-cell death is not fully understood. It is, however, likely to be a combination of antibodydependant cell-mediated cytotoxicity, complement-mediated lysis, growth inhibition and apoptosis. In vivo experiments using a mouse model of immunotherapy suggest that the most important mechanism of action is via antibody-dependant cell-mediated cytotoxicity [1-6]. The mechanisms do, however, work in a complex manner. For example, lymphoma cells at different maturation stages respond differently to Rituximab induced apoptosis and inhibition of proliferation.

Rituximab was first approved by the FDA in 1997 for treatment of patients with relapsed or refractory lymphoma. Since that time, its therapeutic range has gradually expanded to also include nonmalignant B-cell dependent diseases. Of these, rheumatoid arthritis (RA) is the autoimmune disease in which Rituximab has been most extensively studied [4-8].

\section{Drug safety and adverse events}

The tolerability and safety of Rituximab has been well described in the clinical trials of patients with RA and review articles on nonHodgkin's lymphoma [4,7-10]. The most frequent adverse events are infusion reactions (30-35\% with the first infusion). Patients may experience immediate infusion reactions of mild and transient character [4,7-11]. Nevertheless, severe infusion reactions are uncommon and their frequency is reduced by the use of concomitant intravenous steroids. Serum sickness reactions occur more frequently in patients with autoimmune diseases. As Rituximab is a chimeric human/mouse antibody, human antichimeric antibodies (HACAs) may occur and have been reported in about $9.2 \%$ of patients with RA. These HACAs may be responsible for infusion reactions $[9,10]$.

The main concern with the use of Rituximab in the treatment of autoimmune diseases, especially when used with concomitant immunosuppressive therapy, is the high incidence of systemic infections, which can sometimes lead to fatal septicemia [9-11]. Variable degrees of rituximab-associated infectious risk have been reported. Some patients with refractory autoimmune diseases, who were treated with combined rituximab and immunosuppressants, developed infectious complications. Conversely, no infectious complications have been reported for patients in whom Rituximab was initiated alone, without systemic corticosteroids or other immunosuppressants [10]. To date, no studies comparing the infectious risk of conventional immunosuppressants versus Rituximab are available.

\section{Rituximab in systemic autoimmune diseases}

Several clinical studies have demonstrated the substantial impact of rituximab for treatment of various systemic autoimmune diseases [1$8,10-17]$. Evidence of therapeutic effect is also mounting for numerous autoimmune conditions such as rheumatoid arthritis, systemic lupus erythematosus (SLE), Wegener's granulomatosis and anti-neutrophil cytoplasmic antibody (ANCA)-associated vasculitis, idiopathic thrombocytopenic purpura, multiple sclerosis and Sjogren's syndrome [4,7,12-15]. However, the treatment protocols applied in these studies differ from each other in that infusions were given once weekly for 2 to 4 weeks, and the dosages were either fixed at $500 \mathrm{mg}$ or $2000 \mathrm{mg}$ or were $375 \mathrm{mg} / \mathrm{m}^{2}$ in other studies. A sustained B-cell depletion of naïve and autoimmune cells was achieved, with peripheral blood CD20 cells being low or undetectable for up to 6 months, returning to pretreatment levels within 12 months. Earlier repopulation of B cells was observed after rituximab monotherapy rather than after combination therapy with immunosuppressive agents, such as methotrexate [2].

\section{Rituximab in inflammatory eye diseases}

Rituximab has been successfully used for the treatment of refractory keratoconjunctivitis, scleritis [18-23], peripheral ulcerative keratitis [24,25], uveitis [26-29] and ocular surface inflammatory diseases such as cicatricial pemphigoid $[30,31]$ also when associated with systemic diseases. Experience in inflammatory ocular diseases is still scarce with few case reports on its efficacy.

\section{Scleritis and orbital inflammation}

Necrotizing scleritis and peripheral ulcerative keratitis are destructive forms of ocular inflammation of Wegener's granulomatosis usually associated with active systemic vasculitis and can result in profound visual loss. Successful effectiveness with Rituximab has been reported on three patients with scleritis and peripherative ulcerative keratitis associated with Wegener's granulomatosis [18,20-23]. Another case of peripherative ulcerative keratitis associated to Wegener's granulomatosis completely resolved with two Rituximab infusions, given according to the protocol of $1000 \mathrm{mg} /$ infusion at two weeks apart [24]. Some authors showed limited evidence that scleritis and orbital inflammation may respond to Rituximab, probably due to the presence of fibrotic nature of granulomas in Wegener's, especially when occurring retroorbital [22]. Taylor and colleagues reported clinical improvement in 10 patients with refractory granulomatous ocular Wegener's mainly scleritis and orbital granulomas [21]. In the study by Taylor, patients were treated with 2 doses of $1 \mathrm{mg}$ each, 2 weeks apart, and B cell depletion was associated with a trend toward decreased ANCA levels and clinical improvement in both vasculitic and granulomatous manifestations of the disease [21]. Ahmadi-Simab and colleagues reported a case of refractory anterior scleritis associated with Sjögren's syndrome that completely resolved after four infusions of Rituximab given according to the oncologic protocol at the dose of $375 \mathrm{mg} / \mathrm{m}^{2}$ at four-week intervals [19]. It is possible that the different dosing regimens used for refractory orbital inflammation associated with Wegener granulomatosis may be responsible for the reported different responses.

\section{Sjogren's syndrome}

Keratoconjunctivitis sicca (KCS) is the most common ocular manifestation of Sjogren's syndrome; sicca syndrome, secondary to lacrimal gland inflammation and reduction of lacrimal tear secretion can induce severe corneal complications and may eventually lead to bilateral blindness.

Preliminary experiences of Rituximab therapy in Sjogren's syndrome patients suggest that patients with more residual exocrine gland function might better benefit from treatment. Sicca syndrome responded much better in the patient's perspective than in clinical objective evaluation, with about half of the patients reporting an improvement in oral and ocular dryness, while objective tests (Schirmer test) remained unchanged or worsened in all the patients $[16,17]$. Improvement in submandibular flow rate, dry mouth score, IgM rheumatoid factors (RF), fatigue, and health-related quality of life tests, was also observed in Sjogren's patients after treatment with Rituximab [17].

\section{Ocular cicatricial pemphigoid}

Ocular cicatricial pemphigoid (OCP) is one of the subsets within the spectrum of mucous membrane pemphigoid, a family of autoimmune blistering diseases with autoantibodies targeting various glycoproteins in skin and/or mucous membranes [30]. The disease is relentlessly progressive, usually slow, and often resulting in profound 
visual disability. Foster and colleagues reported effective results on twelve patients with OCP treated with a combination of Rituximab and intravenous immunoglobulin therapy [31].

\section{Intraocular lymphoma}

Primary intraocular lymphoma, is a hematopoietic tumor that arises within the retina, vitreous, subretinal pigment epithelial space or optic nerve head. Intraocular lymphoma may manifest with different forms of uveitis called "masquerade syndrome". The malignancy is considered a subset of primary central nervous system lymphoma, which is a variant of extra-nodal non Hodgkin lymphoma. Malignant lymphocytes present in intraocular lymphoma express certain B cell markers including CD 20 [32]. Therefore, intraocular use of rituximab has been explored in animal models. No ocular toxicity was found in rabbits and in humans treated with $1 \mathrm{mg}$ of Rituximab injected in the vitreous cavity. Further studies are necessary to confirm the lack of toxicity at this dose and whether this local therapy is effective in human intraocular lymphoma [32,33].

\section{Uveitis}

Rituximab may be helpful in selected patients with chronic uveitis refractory to corticosteroid and conventional immunosuppressants. Tappeiner and colleagues reported improvement of endogenous uveitis and associated cystoid macular edema in an adult patient treated with Rituximab; the treatment also displayed a steroidsparing effect. However, the B-cell depletion in the peripheral blood and the positive effect on uveitis were transient, since there was a recurrence of inflammation after 6 and 9 months from Rituximab treatment [26].

Davatchi and Sadreddini showed favorable results on the efficacy of Rituximab in intractable ocular lesions of patients with Behcet's disease, in spite of the fact that it is mainly a T-cell driven disease $[27,28]$.

\section{Children with juvenile idiopathic arthritis associated uveitis: personal experience}

Juvenile idiopathic arthritis (JIA) is the most common systemic disorder associated with uveitis in childhood, accounting for approximately $75 \%$ of all pediatric anterior uveitis cases. Long-term ocular complications of uveitis such as cataract, band keratopathy, posterior synechia, glaucoma and maculopathy can lead to severe visual impairment in about 38\% of patients [34]. Visual outcome in longterm follow-up of patients suffering from JIA-associated uveitis has been described as poor, with one third of patients developing substantial visual impairment and 10\% becoming blind [34]. Aggressive immunomodulatory therapy is often introduced to improve the visual prognosis and to reduce corticosteroid associated adverse events. With the advent of biologic agents, tumor necrosis factor $\alpha$ (TNF $\alpha$ ) antagonists have been successfully used and have changed and markedly improved the treatment options for JIA [35-37]. However, a subset of patients fails to respond to TNF $\alpha$ blockers or is unable to tolerate these therapies and may benefit from switching to another drug.

B cells are clearly involved in the pathogenesis of oligoarticular JIA and associated uveitis, as suggested not only by the very strong association with ANA production in this JIA subset, but also by recent studies on peripheral blood mononuclear cells gene expression profile showing that B cell receptors signaling pathways is strongly upregulated in patients with persistent oligoarthritis [38]. Therefore B cells may be a rational target of biological treatment in JIA associated uveitis. Based on this and on the favorable response in inducing longterm remissions in different ocular and rheumatic inflammatory diseases, we decided to treat with Rituximab eight patients with recalcitrant and longstanding chronic JIA associated uveitis. We previously reported our preliminary experience with Rituximab in children with uveitis associated with JIA [39].

All patients attended the Pediatric Rheumatologic Unit at the "Istituto Ortopedico G. Pini", Milan and were always under the care of the same uveitis specialist (EM). Patients included in the study were those who had an inadequate response in controlling intra-ocular inflammation to one or more TNF blockers (Etanercept, Infliximab or Adalimumab). Rituximab was given at the dose of $1000 \mathrm{mg}$ per infusion on days 1 and 15 and a recall 3rd infusion was scheduled at 12th month and 21 months according to the rheumatologic protocol applied in the treatment of rheumatoid arthritis. Before Rituximab infusion, to prevent the onset or reduce the frequency and severity of infusion reactions, all patients received $100 \mathrm{mg}$ of methylprednisolone intravenously, oral paracetamol and antihistamines. Screening before initiation of Rituximab treatment included serum biochemical and hematologic profiles with complete hemogram, liver and renal function tests, peripheral blood B lymphocytes count, chest X-ray and electrocardiography. All patients have been already pre-screened for the presence of active or latent tuberculosis since they have been previously treated with TNF-blockers.

Ophthalmic and rheumatologic assessments were performed every one or two months according to disease activity and response to treatment. All patients were clinically monitored by the same pediatric rheumatologist (IP) with complete physical examination and routine laboratory test, repeated at each office visit. Data collected included: age, gender, age at onset of uveitis and arthritis, characteristics of the uveitis, ocular complications, JIA category according to ILAR classification [40], presence of ANA, RF and HLA-B27 antigens, previous systemic immunosuppressant therapies, previous local (ocular) corticosteroid therapy, number and dosage of Rituximab infusions, and follow-up on Rituximab treatment.

The primary outcome measures evaluated were: clinical response to treatment including decrease in disease activity (intra-ocular inflammation), improvement in visual acuity, reduction of concomitant local and systemic corticosteroid and/or immunosuppressants, occurrence of adverse events. Disease activity was graded in accordance with the standardization uveitis nomenclature (SUN) criteria [41]. Anterior chamber cells, as a validated indicator for inflammatory activity and Snellen visual acuity were graded before treatment and at every ophthalmologic assessment.

Eight Caucasian patients ( 2 males and 6 females; 14 affected eyes) with a mean age of $20.26 \pm 6.6$ (SD) years (range: 13-34) affected by JIA (oligo-extended in 5 patients, oligo-persistent in 2) and associated uveitis were treated with Rituximab. Treatment indication was active uveitis and failure to conventional immunosuppressants and anti-TNF agents (Etanercept, Infliximab, Adalimumab) due to inadequate response. All patients were ANA positive and negative for RF and HLA-B27 antigens. The mean age at onset of arthritis was $2.8 \pm 2.4$ (SD) years (range 1-8), while the mean age at onset of uveitis was $4.1 \pm 3.9$ (SD) years (range 1-12); the mean ocular disease duration was 16.12 years (range 11-26) and the mean duration of arthritis was 17.35 years (range 11-26). In six out of eight patients the ocular involvement was bilateral (total number of treated eyes: 14). Ocular complications present at the beginning of Rituximab treatment were: posterior synechia (13 out of 14 affected eyes), cataract (8/14 eyes), band keratopathy (11/14 eyes), glaucoma (5/14 eyes). Table 1 shows the details of previous and concomitant treatments for each patient.

Before starting the Rituximab treatment, all patients have been unsuccessfully treated with different consecutive TNF $\alpha$ blockers; patients \#4 and \#6 were switched on two agents, while the remaining patients underwent a switch of three different anti-TNF. The reason for switching among anti-TNF was either inefficacy on the uveitis or occurrence of adverse events. Patients \#5 and \#8 were also treated with a short-term course of chlorambucil before and after being treated with TNF blockers. Although long-term remission with 
Table 1

Previous and current treatments: previous and current immunosuppressants employed, previous anti-TNF employed, previous local and systemic corticosteroids employed.

\begin{tabular}{|c|c|c|c|c|c|}
\hline $\begin{array}{l}\text { Pt } \\
\text { no. }\end{array}$ & $\begin{array}{l}\text { Immunosuppressants } \\
\text { employed before rituximab }\end{array}$ & $\begin{array}{l}\text { Anti-TNF drugs employed } \\
\text { before rituximab (switch) }\end{array}$ & $\begin{array}{l}\text { Immunosuppressants } \\
\text { employed at last visit }\end{array}$ & $\begin{array}{l}\text { Systemic steroid before rituximab and at } \\
\text { last visit (prednisolone } \mathrm{mg} / \text { day) }\end{array}$ & $\begin{array}{l}\text { Topical steroids before rituximab and } \\
\text { at last visit (daily frequency) }\end{array}$ \\
\hline 1 & MTX, CSA & Etan, Infl, Adal & None & 7.5-None & $3-1$ \\
\hline 2 & MTX, CSA & Etan, Infl, Adal & None & 25-12.5 & $4-1$ \\
\hline 3 & MTX, CSA & Etan, Infl, Adal & None & None-None & $4-2$ \\
\hline 4 & MTX, CSA, AZA & Infl, Adal & CSA & 25-12.5 & $3-1$ \\
\hline 5 & MTX, CSA, CHLOR & Etan, Infl, Adal & MTX & $20-12.5$ & $6-0$ \\
\hline 6 & MTX, CSA & Etan, Infl & None & 15-None & $2-0$ \\
\hline 7 & MTX & Etan, Infl, Adal & MTX, CSA & None-None & $2-1$ \\
\hline 8 & MTX, CSA, CHLOR & Etan, Infl, Adal & None & $20-2.5$ & $2-1$ \\
\hline
\end{tabular}

Legend: MTX: methotrexate; CSA: cyclosporine; CHLOR: chlorambucil; Etan: etanercept; Infl:infliximab; and Adal: adalimumab.

Chlorambucil agents has been previously reported in our experience with JIA associated uveitis patients [42], two of our patients failed to respond to this immunosuppressive agent. Patients \#5 and \#8, before or after switching of three anti-TNF drugs, have also tried a one-year course of Chlorambucil treatment with long-term remission but flare up of the uveitis after cessation of the alkylating agent.

The mean systemic prednisolone dose needed before Rituximab treatment was $18.75 \mathrm{mg} /$ day (range 7.5-25 mg). At the end of followup, only four out of six patients were still on daily systemic low-doses of prednisolone (2.5-12.5 mg). The six patients treated with systemic prednisolone, were able to greatly reduce the number of daily topical corticosteroid drops, from a mean of 3.25 (range 6-2) to a mean of 0.8 (range 2-0) times a day, and the remaining two patients were able to discontinue topical therapy.

The mean follow-up time on Rituximab was $14.87 \pm 7.12$ (SD) months (range: 7-25). Four out of eight patients (\#1, \#2, \#4 and \#7) underwent the 3rd Rituximab recall infusion after 8-12 months from the first one, and pt \#3 underwent the 4th recall infusion after 21 months from the first one, while the remaining received only the first full course of therapy of two infusions (Table 2).

Seven out of eight patients achieved the complete control of the uveitis and were on persistent clinical remission at the last visit. Patient \#1 displayed a recurrence of anterior uveitis that resolved with topical corticosteroids, at 10th month after the first full course of Rituximab, Patient \# 3 had two recurrences respectively at 8th and 21 months, and underwent to an early recall 3rd and 4th infusion.

The decrease in uveitis activity was evident around the 4th-5th month after the first infusion. Snellen visual acuity measurements of

Table 2

Clinical response to rituximab, follow-up and visual acuity data, dose and number of rituximab infusions.

\begin{tabular}{|c|c|c|c|c|c|c|}
\hline $\begin{array}{l}\mathrm{Pt} \\
\text { no. }\end{array}$ & $\begin{array}{l}\text { Activity } \\
\text { of } \\
\text { uveitis } \\
\text { at last } \\
\text { visit }\end{array}$ & $\begin{array}{l}\text { Recurrence of } \\
\text { uveitis } \\
\text { (months from } \\
\text { first infusion) }\end{array}$ & $\begin{array}{l}\text { Follow-up } \\
\text { time on } \\
\text { rituximab } \\
\text { (months) }\end{array}$ & $\begin{array}{l}\text { Visual } \\
\text { acuity } \\
\text { before } \\
\text { rituximab }\end{array}$ & $\begin{array}{l}\text { Visual } \\
\text { acuity } \\
\text { at last } \\
\text { visit }\end{array}$ & $\begin{array}{l}\text { No. of rituximab } \\
\text { infusions } \\
\text { ( } 1000 \mathrm{mg} \text { : dose } \\
\text { at each infusion) }\end{array}$ \\
\hline 1 & No & 10 & 25 & $\begin{array}{l}\text { 20/40; } \\
\text { NLP }\end{array}$ & $\begin{array}{l}20 / 40 \\
\text { NLP }\end{array}$ & 3 \\
\hline 2 & No & No & 23 & $\begin{array}{l}20 / 40 \\
20 / 200\end{array}$ & $\begin{array}{l}20 / 40 \\
20 / 40\end{array}$ & 3 \\
\hline 3 & Yes & 8,21 & 21 & $\begin{array}{l}20 / 20 \\
20 / 20\end{array}$ & $\begin{array}{l}20 / 20 \\
20 / 20\end{array}$ & 4 \\
\hline 4 & No & No & 14 & $\begin{array}{l}20 / 20 \\
20 / 25\end{array}$ & $\begin{array}{l}20 / 20 \\
20 / 25\end{array}$ & 3 \\
\hline 5 & No & No & 11 & $\begin{array}{l}20 / 60 \\
20 / 40\end{array}$ & $\begin{array}{l}20 / 60 \\
20 / 40\end{array}$ & 2 \\
\hline 6 & No & No & 10 & $\begin{array}{l}\text { 20/20; } \\
\text { NLP }\end{array}$ & $\begin{array}{l}\text { 20/20; } \\
\text { NLP }\end{array}$ & 2 \\
\hline 7 & No & No & 8 & $\begin{array}{l}20 / 20 \\
20 / 20\end{array}$ & $\begin{array}{l}20 / 20 \\
20 / 20\end{array}$ & 3 \\
\hline 8 & No & No & 7 & $\begin{array}{l}\text { NLP; } \\
20 / 60\end{array}$ & $\begin{array}{l}\text { NLP; } \\
20 / 60\end{array}$ & 2 \\
\hline
\end{tabular}

Legend. NLP: no light perception. each patient at the beginning of Rituximab and at last visit are shown in Table 2. None of the patients had a visual worsening during the follow-up, while one patient (\#2) had a visual acuity improvement of the left eye being able to undergo cataract surgery while on clinical remission on Rituximab treatment. No serious adverse events were encountered in our treated patients.

The uveitis was on clinical remission in seven out of eight patients at the last visit and improvement of intra-ocular inflammation was noticeable around the 4th month after the first infusion of Rituximab.

A corticosteroid sparing effect of Rituximab was noticeable in all our patients; four out of six patients taking systemic prednisolone were still on tapering daily low doses at the end of follow-up, but the dosage was significantly reduced compared to that required at the beginning of Rituximab (mean reduction $-11.7 \mathrm{mg}$ /day; range -7.5 to -15 ), and two patients discontinued systemic steroid therapy at the end of follow-up. There was also a discontinuation of concomitant systemic immunosuppressants in five out of eight patients; only three patients were taking methotrexate and/or cyclosporine in association with Rituximab treatment at last visit.

Although experience in inflammatory eye disease is scarce, and definite conclusions cannot be drawn by our series because of its retrospective nature and the number of patients we believe that Rituximab may be a promising treatment option for refractory uveitis associated to JIA.

\section{Take-home messages}

- Rituximab, a humanized monoclonal antibody targeted to CD20, has been used extensively for treating systemic lymphoma, rheumatoid arthritis and other autoimmune diseases.

- Rituximab may be effective in the treatment of ocular inflammatory diseases in particular the most aggressive, recalcitrant and sightthreatening forms of inflammation such as uveitis in children associated with JIA, as well as diseases not responsive to anti-TNF alpha blocking agents.

- Inflammatory ocular diseases treated with Rituximab include: scleritis, peripheral ulcerative keratitis, keratocnjunctivitis sicca, uveitis, ocular cicatricial pemphigoid and intraocular lymphoma.

- Rituximab does not cure the disease and recurrences of inflammation are possible; retreatment may be required after variable periods of clinical remission.

- Studies in larger numbers of patients are needed to better evaluate the efficacy, dosing regimen, and safety.

\section{References}

[1] Blank M, Shoenfeld Y. B cell targeted therapy in autoimmunity. J Autoimmun 2007;28:62-8.

[2] Perosa F, Favoino E, Caragnano MA, Prete M, Dammacco F. CD20: a target antigen for immunotherapy of autoimmune diseases. Autoimmun Rev 2005;4:526-31.

[3] Bosello S, De Luca G, Tolusso B, et al. B cells in systemic sclerosis: a possible target for therapy. Autoimmun Rev Apr 222011 [Epub ahead of print]. 
[4] De Vita S, Quartuccio L. Treatment of rheumatoid arthritis with rituximab: an update and possible indications. Autoimmun Rev 2006;5:443-8.

[5] Dörner T, Isenberg D, Jayne D, Wiendl H, Zillikens D, Burmester G. International roundtable on B cells as therapeutic target for intervention. Current status on Bcell depletion therapy in autoimmune diseases other than rheumatoid arthritis. Autoimmun Rev 2009 Dec;9(2):82-9.

[6] Benucci M, Manfredi M, Puttini PS, Atzeni F. Predictive factors of response to rituximab therapy in rheumatoid arthritis: what do we know today? Autoimmun Rev 2010 Oct;9(12):801-3.

[7] Emery P, Fleishmann R, Filipowicz A, Schechtman J, Szczepanski L, Kavanaugh A, et al. The efficacy and safety of rituximab in patients with active rheumatoid arthritis despite methotrexate treatment: results of a phase IIB randomized, double-blind, placebo-controlled, dose-ranging trial. Arthritis Rheum 2006;54: 1390-400.

[8] Smolen JS, Keystone EC, Emery P, Breedveld FC, Betteridge N, Burmester GR. Consensus statement on the use of rituximab in patients with rheumatoid arthritis. Ann Rheum Dis 2007;66:143-50.

[9] Kimby E. Tolerability and safety of rituximab (MabThera). Cancer Treat Rev 2005;31:456-73.

[10] Visentini M, Ludovisi S, Petrarca A, Pulvirenti F, Zaramella M, Monti M, et al. A phase II, single-arm multicenter study of low-dose rituximab for refractory mixed cryoglobulinemia secondary to hepatitis $\mathrm{C}$ virus infection. Autoimmun Rev May 5 2011 [Epub ahead of print].

[11] Kong JSW, Teuber SS, Gershwin ME. Potential adverse events with biologic response modifiers. Autoimmun Rev 2006;5:471-85.

[12] Garcia-Carrasco M, Jimenez-Hernandez M, Escarcega RO, Mendoza-Pinto C, Galarza-Maldonado C, Sandoval-Cruz M. Use of rituximab in systemic lupus erythematosus: an update. Autoimmun Rev 2009;8:343-8.

13] Conti F, Perricone C, Ceccarelli F, Valesini G. Rituximab treatment of systemic lupus erythematosus in controlled trials and in clinical practice: two sides of the same coin. Autoimmun Rev 2010;9:716-20.

[14] Stasi R, Stipa E, Del Poeta G, Amadori S, Newland AC, Provan D. Long-term observation of patients with anti-neutrophil cytoplasmic antibody-associated vasculitis treated with rituximab. Rheumatology 2006;45:1432-6.

[15] Eriksson P. Nine patients with anti-neutrophil cytoplasmic antibody-positive vasculitis successfully treated with rituximab. J Intern Med 2005:257:540-8.

[16] Tobon GJ, Per JO, Youinou P, Saraux A. B cell-targeted therapies in Sjogren's syndrome. Autoimmun Rev 2010;9:224-8.

[17] Quartuccio L, Fabris M, Salvin S, Maset M, De Marchi G, De Vita S. Controversies on Rituximab therapy in Sjogren syndrome-associated lymphoproliferation. Int J Rheumatol 2009;10:1-8.

[18] Onal S, Kazokoglu H, Koc A, Yavuz S. Rituximab for remission induction in a patient with relapsing necrotizing scleritis associated with limited Wegener's granulomatosis. Ocul Immunol Inflamm 2008;16:230-2.

[19] Ai M, Gross WL, Ahmadi-Simab K, Lamprecht P, Nolle B. Successful treatment of refractory anterior scleritis in primary Sjogren's syndrome with rituximab. Ann Rheum Dis 2005;64:1087-8.

[20] Cheung CM, Murray PI, Savage CO. Successful treatment of Wegener's granulomatosis associated scleritis with rituximab. $\mathrm{Br} \mathrm{J}$ Ophthalmol 2005;89:1542.

[21] Taylor SRJ, Salama AD, Joshi L, Pusey CD, Lightman SL. Rituximab is effective in the treatment of refractory ophthalmic Wegener's granulomatosis. Arthritis Rheum 2009;60:1540-7.

[22] Aries PM, Hellmich B, Voswinkel J, Both M, Nölle B, Holl-Ulrich K. Lack of efficacy of rituximab in Wegener's granulomatosis with refractory granulomatous manifestations. Ann Rheum Dis 2006;65:853-8.
[23] Kurz PA, Suhler EB, Choi D, Rosenbaum JT. Rituximab for treatment of ocular inflammatory disease: a series of four cases. Br J Ophthalmol 2009;93:546-8.

[24] Freidlin J, Wong IG, Acharya N. Rituximab treatment for peripheral ulcerative keratitis associated with Wegener's granulomatosis. Br J Ophthalmol 2007;91:1414.

[25] Huerva V, Sanchez MC, Traveset A, Jurjo C, Ruiz A. Rituximab for peripheral ulcerative keratitis with Wegener granulomatosis. Cornea 2010;29(6):708-10.

[26] Tappeiner C, Heinz C, Specker C, Heilighenhaus A. Rituximab as a treatment option for refractory endogenous anterior uveitis. Ophthalmic Res 2007;39:184-6.

[27] Davatchi F, Shams H, Rezaipoor M, Sadeghi-Abdollahi B, Shahram F, Nadji A, et al. Rituximab in intractable ocular lesions of Behcet's disease; randomized single-blind control study (pilot study). Int J Rheum Dis 2010;13:246-52.

[28] Sadreddini S, Noshad H, Molaeefard M, Noshad R. Treatment of retinal vasculitis in Behcet's disease with rituximab. Mod Rheumatol 2008;18:306-8.

[29] Hickman RA, Denniston AK, Yee CS, Toescu V, Murray PI, Gordon C. Bilateral retinal vasculitis in a patient with systemic lupus erythematosus and its remission with rituximab therapy. Lupus 2010;19:327-9.

[30] Anhalt GJ, Morrison LH. Bullous and cicatricial pemphigoid. J Autoimmun 1991;4: 17-35.

[31] Foster CS, Chang PY, Ahmed RM. Combination of rituximab and intravenous immunoglobulin for recalcitrant ocular cicatricial pemphigoid. A preliminary report. Ophthalmology 2010;117:861-9.

[32] Kitzmann AS, Pulido JS, Mohney BG, Baratz KH, Grube T, Marler RJ. Intraocular use of rituximab. Eye 2007;21:1524-7.

[33] Ohguro N, Hashida N, Tano Y. Effect of intravitreous rituximab injections in patients with ocular lesions associated with central nervous system lymphoma. Arch Ophthalmol 2008;126:1002-3.

[34] Kump LI, Cervantes Castaneda RA, Androudi SN, Foster CS. Visual outcomes in children with juvenile idiopathic arthritis-associated uveitis. Ophthalmology 2006;113:1874-7.

[35] Foeldvari I, Nielsen S, Kummerle-Deschner J, Espada G, Horneff G, Bica B, et al. Tumor necrosis factor- $\alpha$ blocker in treatment of juvenile idiopathic arthritis-associated uveitis refractory to second-line agents: results of a multinational survey. J Rheumatol 2007:34:1146-50.

[36] Gerloni V, Pontikaki I, Gattinara M, Fantini F. Focus on adverse events of tumour necrosis factor alpha blockade in juvenile idiopathic arthritis in an open monocentric long-term prospective study of 163 patients. Ann Rheum Dis 2008;67:1145-52.

[37] Gallagher M, Quinones K, Cervantes-Castañeda RA, Yilmaz T, Foster CS. Biological response modifier therapy for refractory childhood uveitis. Br J Ophthalmol 2007;91: 1341-4.

[38] Barnes MG, Grom AA, Thompson SD, Griffin TA, Pavlidis P, Itert L, et al. Subtypespecific peripheral blood gene expression profiles in recent-onset juvenile idiopathic arthritis. Arthritis Rheum 2009;60:2102-12.

[39] Miserocchi E, Pontikaki I, Modorati G, Bandello F, Meroni PL, Gerloni V. Rituximab for uveitis. Ophthalmology 2011;118:223-4.

[40] Petty RE, Southwood TR, Manners P, Baum J, Glass DN, Goldenberg J, et al. International League of Associations for Rheumatology classification of juvenile idiopathic arthritis: second revision, Edmonton, 2001. J Rheumatol 2004;31:390-2.

[41] The standardization of uveitis nomenclature (SUN) working group. Standardization of uveitis nomenclature for reporting clinical data. Results of the first International workshop. Am J Ophthalmol 2005;140:509-16.

[42] Miserocchi E, Baltatzis S, Ekong A, Roque M, Foster CS. Efficacy and safety of chlorambucil in intractable noninfectious uveitis: the Massachusetts Eye and Ear Infirmary experience. Ophthalmology 2002;109:137-42.

\section{Antiphospholipid antibodies affect human endometrial angiogenesis.}

A large variety of autoantibodies are described in patients affected with polymyositis (PM) or dermatomyositis (DM), generally associated with clinically distinct disease subsets, or with myositis overlap syndrome.

More recently anti-155/140 and anti-CADM-140 autoantibodies have been described and clinical and prognostic correlations of these antibodies are still under investigation.

In a large multicenter cross-sectional Japanese study (Arch Dermatol 2011; 147:391-8) anti-Mi-2, anti-155/140, and anti-CADM-140 autoantibodies were investigated in 376 Japanese patients affected with DM in order to clarify the correlations between these three DM specific antibodies and clinical features and prognosis. Patients with PM, systemic sclerosis, and systemic lupus erythematosus were also considered in the analysis.

These antibodies were found only in patients affected with DM, and not in patients affected with other autoimmune disease. Anti-Mi-2 antibodies, found positive in $2 \%$ of DM cases were associated with mysositis without pulmonary involvement; anti-155/140 antibodies found positive in $7 \%$ of cases were associated with malignancy; finally, anti-CADM-140 positive patients were $11 \%$ and had clinically amyopathic DM with rapidly progressive interstitial lung disease and higher mortality. 